\title{
WEAR OF ROTARY INSTRUMENTS: A PILOT STUDY
}

A. Abdul Aziz, N.H. Abu Kasim, C. Ramasindarum, M.Y.P. Mohamad Yusof, M. Paiizi, R. Ahmad. Wear of rotary instruments: A pilot study. Annal Dent Univ Malaya 2011; 18: 1-7.

\begin{abstract}
The aim of this study was to assess the wear of tungsten carbide burs and round rotary diamond instruments through measurements of rake angle and visual observations respectively under a field emission scanning electron microscope. Sixty short and long head pear-shaped tungsten carbide burs and 18 round rotary diamond instruments that had been used to complete $<5, \geq 5$ and $\geq 10$ cavity preparations $(n=10 /$ group) were selected from the $3^{\text {rd }}$ and $4^{\text {th }}$ year dental students, Faculty of Dentistry, University of Malaya. There were two control groups consisting of long and short tungsten carbide burs of ten each. Two-way ANOVA was used to analyse the rake angle data. The data from the two control groups were collectively analysed following multiple paired t-test $(p>.05)$ which showed no significant difference between the two types of tungsten carbide bur (short and long head). The mean rake angle of the control group was significantly higher $(\mathrm{p}<.05)$ compared to the $<5, \geq 5$ and $\geq 10$ cavity preparation groups. The rake angle of the $\geq 10$ cavity preparation group was significantly lower than the other two test groups $(p<.05)$. Round rotary diamond instruments in the $<5$ cavity preparation group showed intact diamond particles with distinct cutting facets comparable to the control group. However, diamonds instruments in the $\geq 5$ and $\geq 10$ cavity preparation groups showed blunt diamond particles. In conclusion, wear of tungsten carbide burs and round rotary diamond instruments were evident after repeated use. Wear was more pronounced when instruments were used to prepare more than ten cavities.
\end{abstract}

Key words: tungsten carbide burs; diamond rotary instrument; wear; rake angle

\section{INTRODUCTION}

Rotary instruments have been used for tooth preparation including the removal of demineralized tissues for more than a century. The three most common types currently used are steel, tungsten carbide and diamond. Steel burs perform well when used to cut dentine at low speed but blunt rapidly when cutting enamel at high speed. Once dulled the reduced cutting efficiency of steel burs create increased
Original Article

A. Abdul Aziz ${ }^{1}$, N.H. Abu Kasim¹,

C. Ramasindarum², M.Y.P. Mohamad Yusof ${ }^{3}$, M. Paiizi ${ }^{4}$, R. Ahmad ${ }^{3}$

${ }^{1}$ Department of Conservative Dentistry

${ }^{2}$ Research Management Centre

Faculty of Dentistry, University of Malaya,

50603 Kuala Lumpur, Malaysia.

Tel No (Office): +60379674897

Fax: +603 79674533

Email:azwatee@um.edu.my

${ }^{3}$ Center of Studies in Oral \& Maxillofacial Medicine, Pathology \& Diagnostic

Universiti Teknologi MARA,

Faculty of Dentistry, 40450, Shah Alam,

Selangor, Malaysia.

${ }^{4}$ Pejabat Pergigian Kawasan Penampang,

Peti Surat 799, 89570 Penampang.

Sabah, Malaysia

Corresponding author: Dr. Azwatee Abdul Aziz

heat and vibration, which could be detrimental to the pulp (1).

Tungsten carbide burs, which were introduced in 1947, have since replaced steel burs when high speed headpiece was used. Carbide is stiffer and harder than steel, therefore less prone to wear during cutting. However, it is brittle and tends to fracture by chipping (2). According to Reisbick \& Bunshah (3), the tungsten carbide bur must possess radial or negative rake angles to provide strength against fracture caused by the carbide brittleness. This is in contrast to the positive rake and large relief angles in non-dental cutting tools.

Early diamond rotary instruments were made by hammering diamond powder onto the surface of soft copper or iron blanks (4) while the modern diamond introduced in 1932 by WH Drendrel was fabricated by attaching diamond particles to stainless steel either by sintering or galvanic metal bond (5). Diamond rotary instruments have great clinical impact because of their long service life and great efficiency in cutting both the enamel and dentine.

Repeated use of tungsten carbide burs and diamond rotary instruments is a common practise among dentists. The applied torque during tooth preparation can cause degradation of these rotary instruments thus decreasing its cutting efficiency. Various studies have been conducted to determine the cutting efficiency of both tungsten carbide burs and diamond cutting instruments (2, 6-7), however, literature with regards to wear of these cutting 
instruments after repeated usage for cavity preparations is scarce. Therefore, the aim of this pilot study was to evaluate the wear of repeatedly used tungsten carbide burs and diamond rotary instruments by rake angle measurements and visual examination respectively using field emission scanning electron microscope.

\section{MATERIALS AND METHOD}

Two types of high speed pear-shaped tungsten carbide burs and round rotary diamond instruments (NTI Kahla $\mathrm{GmbH}$, Germany) that have been used by the $3^{\text {rd }}$ and $4^{\text {th }}$ dental students at the Faculty of Dentistry, University of Malaya were selected for this pilot study by checking their project books of clinical schedule from the Department of Conservative Dentistry. These rotary instruments had been assigned to individual students at the beginning of their clinical training in the $3^{\text {rd }}$ academic year.

A total of 60 short head pear shaped (H7-314-010) and long head pear-shaped (H7L-314-012) tungsten carbide burs that have been used to prepare amalgam Class I and II cavities were collected from the $3^{\text {rd }}$ and $4^{\text {th }}$ year dental students who have completed $<5, \geq 5$ and $\geq 10$ cavity preparations ( $n=10$ /group). Twenty new long and short burs constituted two control groups of ten each.

The tungsten carbide burs were imaged using Field Emission Scanning Electron Microscopy (FESEM; FEI, Quanta 200F, United Kingdom) at 140x magnification. The wear of tungsten carbide bur was determined by measuring the rake angle since it can be used to indicate the cutting efficiency of dental burs (Figure 1). The rake angle (Figure 1b) of the tungsten carbide burs in this study was determined by first drawing a straight line from the highest point of the cutting blade. Then a second straight line is drawn to approximate the rake face until the two lines intercept. The angle between these two lines represents the rake angle. The data collected was analysed using two-way
ANOVA (SPSS version 12.0) at confidence interval of $95 \%$. The wear of the cutting edge of the tungsten carbide burs was also documented.

Eighteen round diamond rotary instruments (AA314-09) that have been used by the $3^{\text {rd }}$ and $4^{\text {th }}$ year dental students to complete $<5, \geq 5$ and $\geq 10$ cavity preparations ( $n=6 /$ group) were collected and one new round diamond was used as the control. The diamond rotary instruments were visually examined using scanning electron microscopy. Evidence of wear was indicated by the absence of distinct cutting facets of the diamond particles, which are embedded in the binding material.

\section{RESULTS}

\section{Rake angle of tungsten carbide burs and wear}

The mean rake angle decreases with the number of prepared cavities for the short head tungsten carbide burs. However, there was a slight increase in the mean rake angle for the long head tungsten carbide burs after repeatedly used in the preparation of $\geq 5$ cavities. However, it decreases significantly in the $\geq 10$ cavity preparations group (Figure 2). Since there were no significant differences between the two types of tungsten carbide bur (short and long head) in the control groups following multiple paired t-test $(\mathrm{p}>$ $.05)$, henceforth the data were collectively analysed. Two-way ANOVA indicated significant interaction between bur used and number of cavities prepared as depicted by the plot of estimated marginal means (Figure 3). Multiple comparisons were carried out using Games-Howell post-hoc test as Levene's test indicated that the variance across groups could not be assumed. The rake angle of tungsten carbide burs in the $\geq 10$ cavity preparation group exhibited significantly lower mean compared to the other groups $(p<.05)$ as shown in Table 1 . Figure 4 shows the rake angle of a representative tungsten carbide bur from the $\geq 10$ cavity preparation group. Figure 5 and 6 are representative scanning electron micrographs

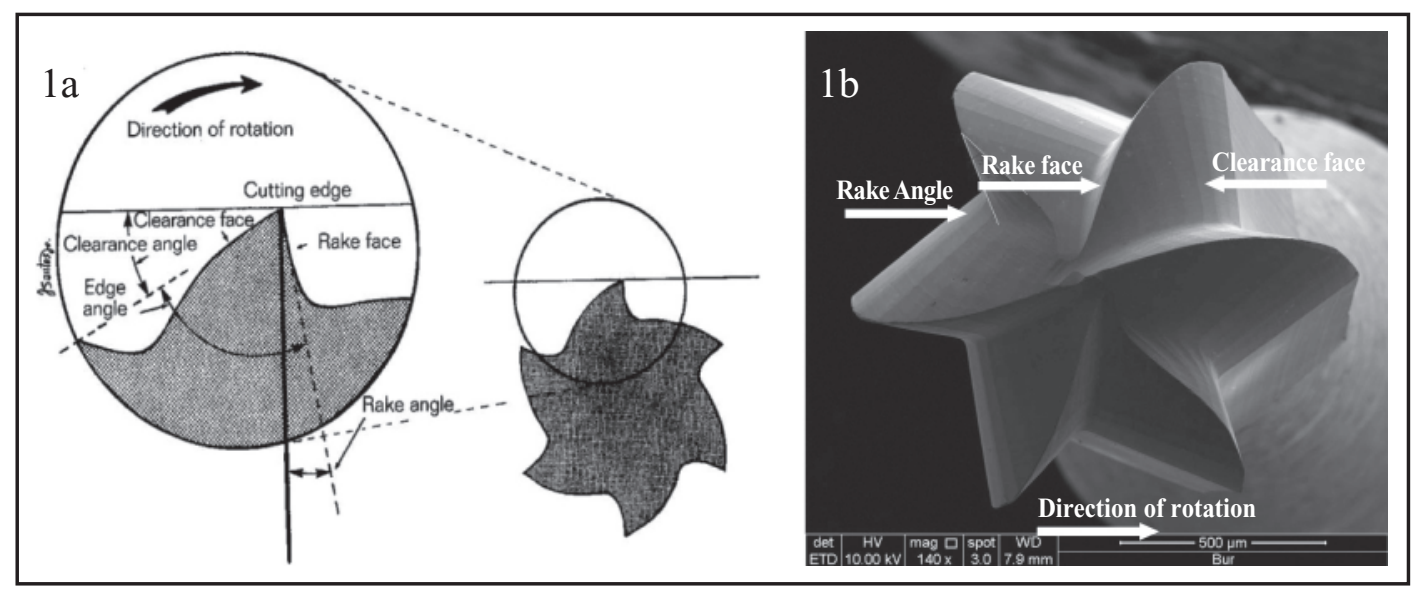

Figure 1. a) Schematic diagram indicating the rake angle of a dental bur (8) and b) Determination of rake angle of a tungsten carbide bur. 


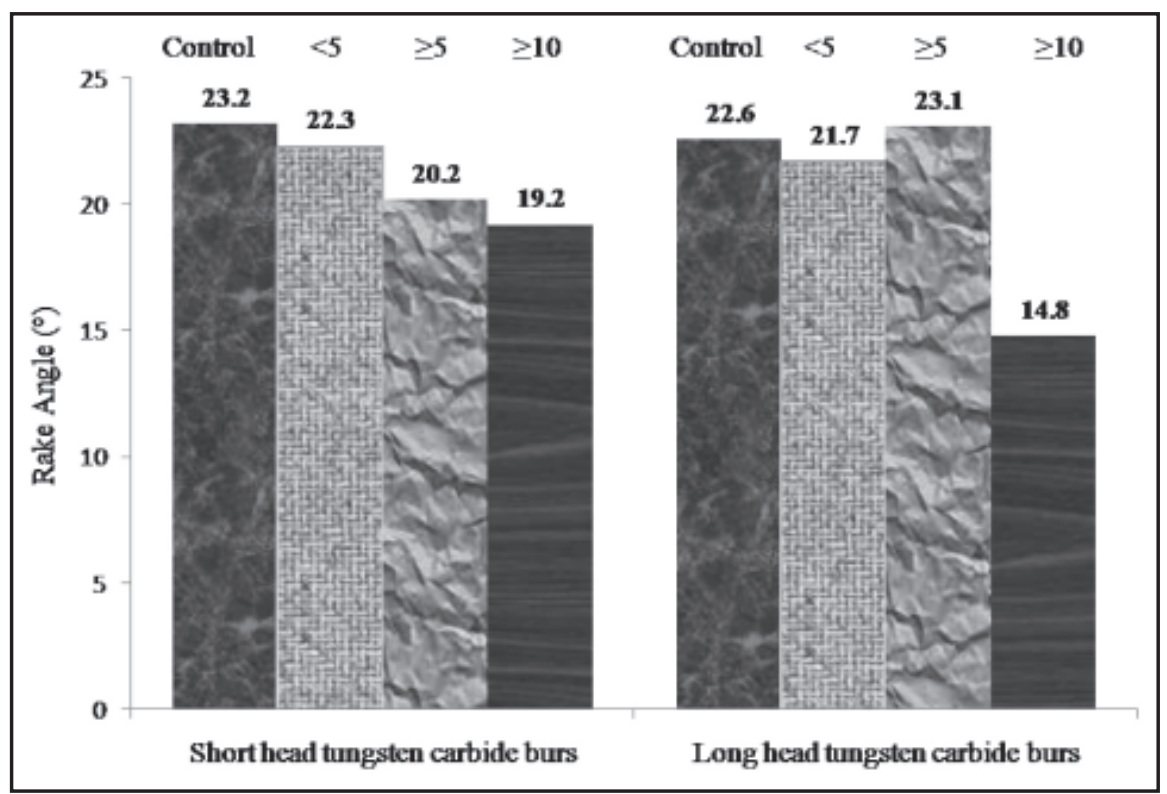

Figure 2. Changes in mean rake angle of tungsten carbide burs after repeated use.

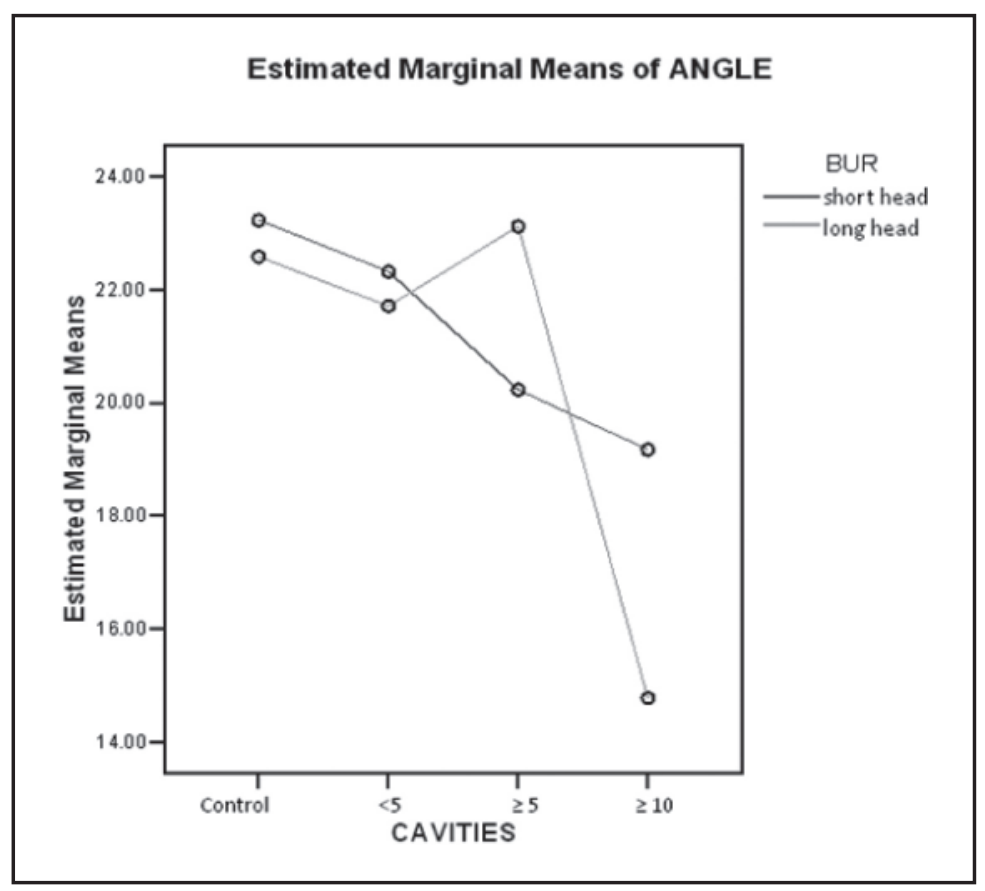

Figure 3. Interaction between number of cavities prepared and type of burs.

Table 1. Multiple comparisons of the mean rake angle

\begin{tabular}{cllcc}
\hline \multirow{2}{*}{ No. of cavities prepared } & \multirow{2}{*}{ Sig. } & \multicolumn{2}{c}{$95 \%$ Confidence Interval } \\
& & & Lower Bound & Upper Bound \\
\hline 0 (Control) & $<5$ & 0.879 & -2.3690 & 4.1490 \\
& $\geq 5$ & 0.784 & -2.3004 & 4.7604 \\
& $\geq 10$ & $0.001^{*}$ & 2.2983 & 9.5617 \\
$<5$ & $\geq 5$ & 0.985 & -2.2729 & 2.9529 \\
& $\geq 10$ & $0.000^{*}$ & 2.2776 & 7.8024 \\
& $\geq 5$ & $0.001^{*}$ & 1.6065 & 7.7935 \\
\hline
\end{tabular}

* Significant at .05 level (Games Howell post hoc test) 


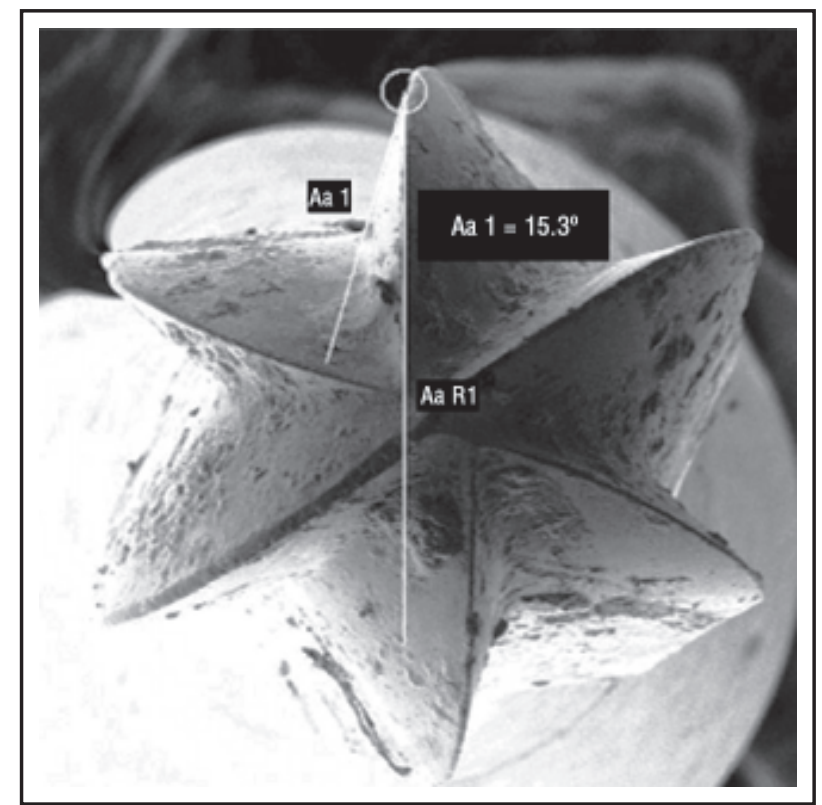

Figure 4. Rake angle of a worn down tungsten carbide bur in the $\geq 10$ cavity preparation group.

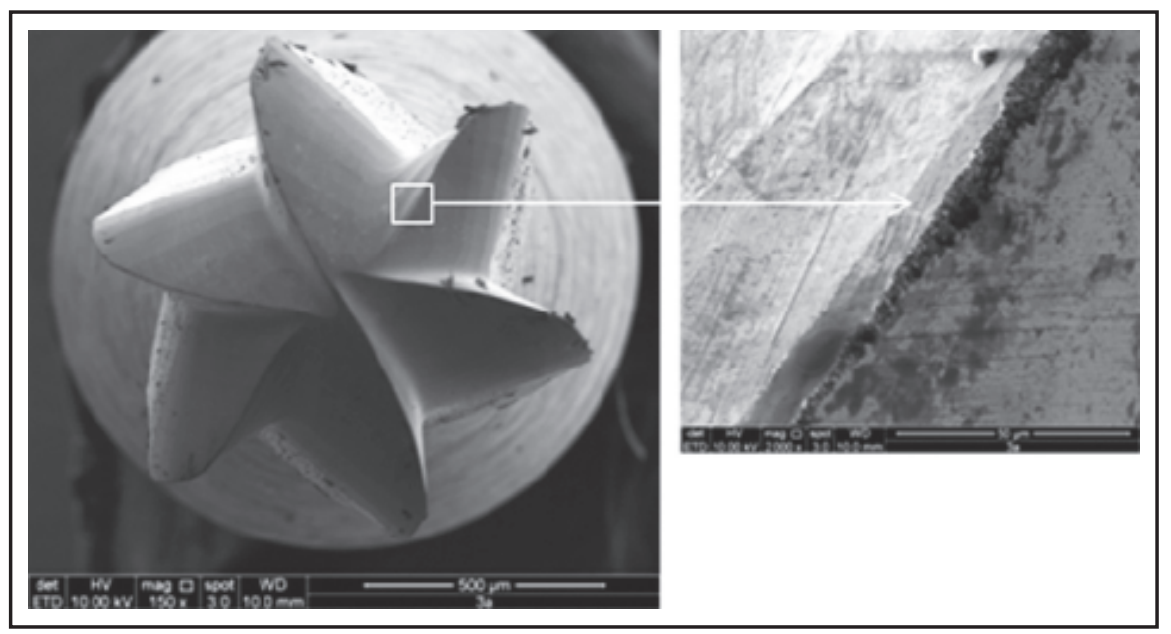

Figure 5. A tungsten carbide bur from the $<5$ cavity preparation group. Each cutting edge showed evidence of wear on higher magnification (2000x).

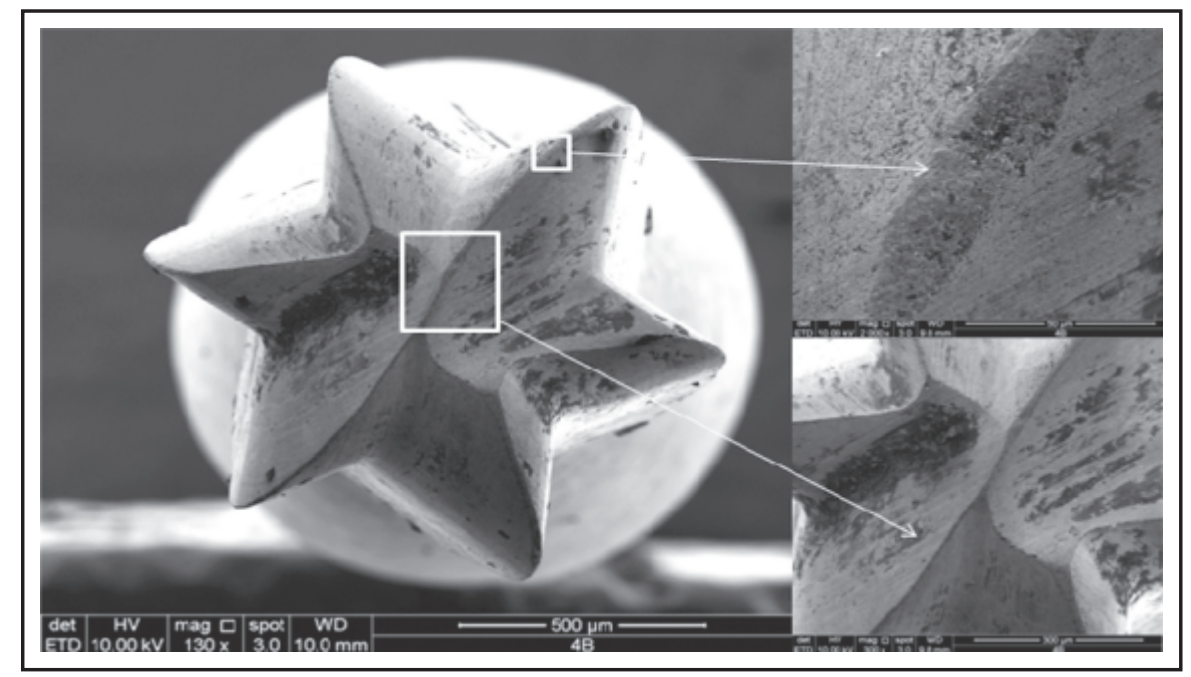

Figure 6. A worn down tungsten carbide bur from the $\geq 5$ cavity preparation group. Blunting of the cutting edge is evident on higher magnification (2000x). 


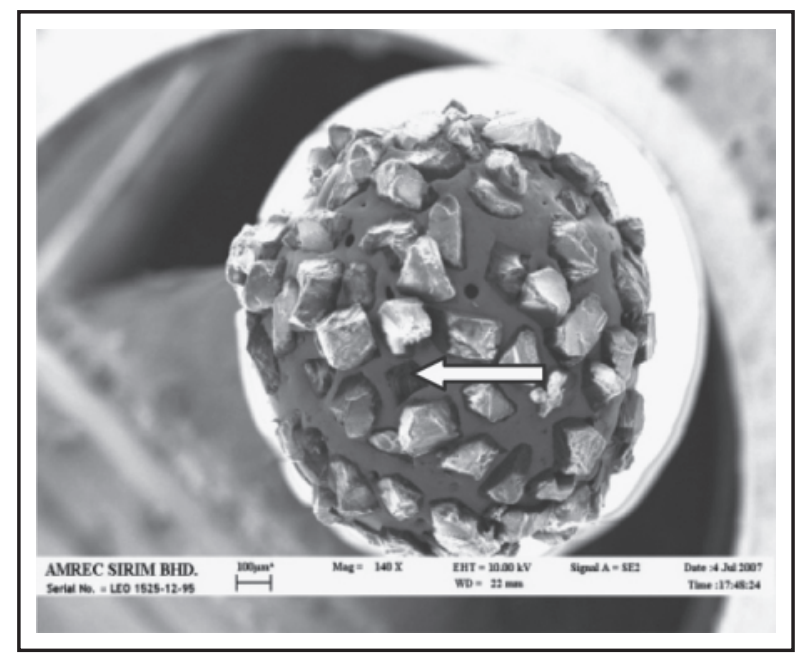

Figure 7. Diamond particles with distinct facets on a new round rotary diamond instrument. The arrow indicates a dislodged diamond particle from the metal binding matrix.

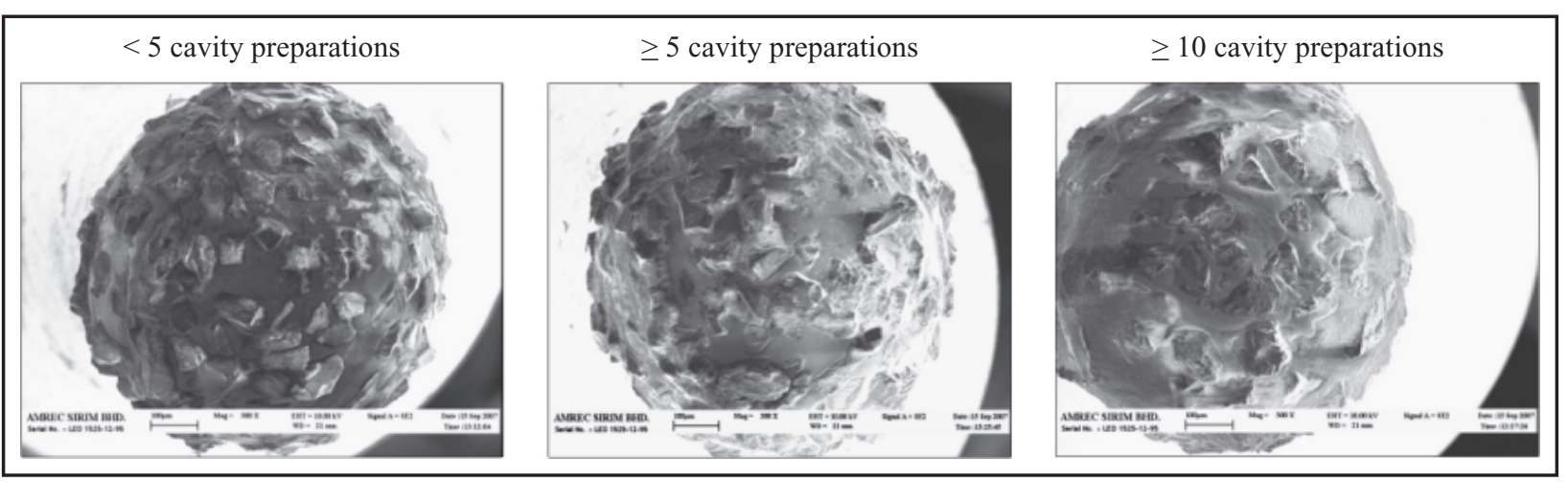

Figure 8. Representative microscopic observations of round rotary diamond from each group. Wear is indicated by the lost of distinct cutting facets of the diamond particles with increasing number of cavities prepared.

depicting the wear of tungsten carbide burs with repeated use to prepare $<5$ and $\geq 5$ cavities.

\section{Wear of round diamond rotary instruments}

Scanning electron micrograph of a new round diamond rotary instrument showed diamond particles with distinct cutting facets (Figure 7). The metal binding matrix also appeared compact, smooth and continuous. Figure 8 is a series of representative micrographs showing various degree of diamond particles deformation when diamond instruments were used repeatedly to prepare $<5, \geq 5$ and $\geq 10$ cavities. Wear was apparent with the lost of distinct cutting facets of the diamond particles. The degree of wear appeared to be closely related to the number of cavities prepared, where low, moderate and high degree of wear can be seen in the $<5, \geq 5$ and $\geq 10$ groups respectively. The metal binding matrix appeared to be very compact and dislodgement of diamond particles was not observed.

\section{DISCUSSION}

The cutting efficiency of rotary diamond instruments and tungsten carbide burs have been reported in many studies $(3,6,9-12)$. Measurements of rake and clearance angles have been used to ascertain the cutting efficiency of carbide burs (13) and the presence of fracture of cutting edge of these types of burs has also been reported (3). In this pilot study, rake angle measurements were carried out as an indication of wear of tungsten carbide burs, where a low rake angle equates to higher wear and vice versa. As dentists often used their rotary instruments repeatedly, this study aimed at gathering preliminary data to determine a methodology in assessing wear of tungsten carbide burs. Although the number of cavities that have been prepared using these burs was estimation, the burs were selected randomly and it could be considered representative of the population. The rake angles for both short and long head tungsten carbide burs 
decreased with the number of cavities prepared for each group indicating wear. Significant difference in the mean rake angle was observed between the $\geq 10$ cavity preparation group and the control (new burs), $<5$ and $\geq 5$ cavity preparation groups. Fracture of the bur cutting edge was also observed. Reisbick and Bunshah (3) suggested that fracture of the cutting edge could lead to improvement of cutting efficiency as a fracture could create a sharper cutting edge. Thus far no study has been carried out to ascertain the cutting efficiency of fractured tungsten carbide burs.

Our data also showed that there was a significant interaction between rake angles and the number of cavities prepared. Lower rake angle indicating greater wear of the cutting blade in the $\geq 10$ cavity preparations group, thus it is likely to cause a decrease in cutting efficiency. This result concurred to Greener and Lindenmeyer (13) study where they reported that dulling reduced the cutting effectiveness after ten cuts. This agreement in results could also indicate that efforts to improve the quality of carbide burs have not been successful. Based on the result of this preliminary study, it is reasonable to recommend that tungsten carbide burs should not be used to cut more than ten cavities. However, a controlled study should be carried out to substantiate this recommendation.

The results of this study also showed that diamond particles remained intact and exhibit distinct cutting facets when used to prepare less than five cavities. Wear of round diamond instrument was most prominent when they were used to prepare more than ten cavities. Wear was characterised by the lost of distinct cutting facets and lesser number of diamond particles. Diamond particles dislodgement should be reflected by the presence of multiple holes in the metal binding matrix, however this was not observed in the micrographs. It is likely that debris has accumulated and appeared homogenous with the metal binding matrix. This result concurred with Pilcher et al. (12) where all their experimental diamond instruments exhibited wear of diamond particles as well as loss of diamond particles and binder after two, ten and twenty preparations.

The density of the diamond particles and the protruding height of diamonds have also been reported to influence cutting efficiency. Deterioration of round diamond instruments after 8 minutes of use was found to be more pronounced for instruments with low particle densities (10). At the same time, if the protruding height of the diamonds is large, the diamond particles can be easily pulled out of the metal binding matrix, long before the diamond particles are worn out (11).

Debris were also observed on the cutting surfaces of rotary dental instruments after being used to prepare $<5, \geq 5$ and $\geq 10$ cavities. Proper cleaning of the rotary cutting instruments prior to sterilization is an important step in the sterilization process and cutting efficiency of the instruments (14). They also reported that instruments must be ultrasonically cleaned, but cleaning solutions with a $\mathrm{pH}$ greater than 11 corroded the metal binding matrix, contributing to diamond particles loss and decreased cutting efficiency. Siegel et al. (15) reported that debris accumulation could be more detrimental to the cutting efficiency of compared to chipping of diamond particles from the rotary dental instruments.

\section{CONCLUSION}

Within the limitations of this study, it can be concluded that:

1. Rake angle measurements could be used to assess wear of pear-shaped tungsten carbide burs. Significantly lower rake angle was observed in the $\geq 10$ cavity preparation group.

2. Round rotary diamond instruments exhibit wear with repeated use and wear was visually more pronounced for instruments in the $\geq 10$ cavity preparation group.

\section{REFERENCES}

1. Roberson T, Heymann H, Swift EJ. Sturdevant's Art $\&$ Science of Operative Dentistry, $4^{\text {th }}$ edition, Mosby Inc. 2002.

2. Atkinson AS. The significance of blade geometry in the cutting efficiency of tungsten carbide dental burs at ultrahigh speeds. Br Dent J 1983; 155: 187193.

3. Reisbick MH, Bunshah RF. Wear Characteristic of Burs. J Dent Res 1973; 52: 1138.

4. Vinski I. Two hundred and fifty of rotary instruments in dentistry. Br Dent J 1979; 146: 217 223.

5. Garg N, Garg A. Text book of Operative Dentistry, $1^{\text {st }}$ edition, Jaypee Brothers Medical Publishers (P) Ltd. 2010.

6. Siegel SC, von Fraunhofer JA. Cutting efficiency of three diamond bur grit sizes. JADA 2000; 131 : 1706-10.

7. Von Fraunhofer JA, Siegel SC. Using chemomechanically assisted diamond bur cutting for improved efficiency. J Am Dent Assoc 2003; 134: 53-8. 
8. Schwartz RS, Summitt JB, Robbins JW. Fundamentals of Operative Dentistry: A Contemporary Approach, 3rd edition, Quintessence. 2006.

9. Janota M. Use of scanning electron microscopy for evaluating diamond points. J Prosthet Dent 1973; 29: 88-93.

10. Grajower R, Zeitchick A, Rajstein J. The grinding efficiency of diamond burs. J Prosthet Dent 1979; 42: 422-28.

11. Borges CFM, Magne P, Pfender E, Heberlein I. Dental diamond burs made with a new technology. J Prosth Dent 1999; 82: 73-78.
12. Pilcher ES, Tietge JD, Draughn RA. Comparison of cutting rates among single-patient-use and multiple-patient-use diamond burs. J Prosthodont 2000; 9: 66-70.

13. Greener EH, Lindenmeyer RS. Bur geometry and its relationship to cutting. J Dent Res 1968; 47 : 87-97.

14. Harkness N, Davies EH. The Cleaning of Dental Diamond Burs. Br Dent J 1983; 154: 42-45.

15. Siegel SC, von Fraunhofer JA. Assessing the cutting efficiency of dental diamond burs. JADA 1996; 127: 763-72. 